\title{
2006-1148: PROJECT PATHWAYS: CONNECTING ENGINEERING DESIGN TO HIGH SCHOOL SCIENCE AND MATHEMATICS IN A MATHEMATICS-SCIENCE PARTNERSHIP PROGRAM
}

\section{Stephen Krause, Arizona State University}

Stephen J. Krause is Professor and an Associate Chair of the Chemical and Materials Engineering Department at ASU. His teaching responsibilities are in the areas of design and selection of materials, general materials engineering, polymer science, and characterization of materials. His research interests are in innovative education in engineering, and structural characterization of polymers and semiconductors. He has co-developed a Materials Concept Inventory for assessing fundamental knowledge of students in introductory materials engineering classes. Most recently, he has been working on Project Pathways, an NSF supported Math Science Partnership, in developing modules for a courses on Connecting Mathematics with Physics and Chemistry and also a course on Engineering Capstone Design

\section{Veronica Burrows, Arizona State University}

Veronica Burrows is Associate Director of the Center for Research on Education in Science, Mathematics, Engineering, and Technology and Associate professor in the Department of Chemical \& Materials Engineering at Arizona State University. She received her B.S. in Chemical Engineering from Drexel University and her Ph.D. in Chemical Engineering from Princeton University. In addition to technical research interest in applied surface chemistry, her engineering education research interests include the learning of engineering modeling, the impact of reflective practice in learning engineering, authentic assessment methods, and "girl-friendly" education.

\section{Vincent Pizziconi, Arizona State University}

Vincent Pizziconi is an Associate Professor in the Bioengineering Department at ASU. His teaching responsibilities are in the areas of introductory engineering, engineering design and biomaterials. His research interests are in innovative education in engineering and on the development of molecular, cellular and tissue strategies to develop bioresponsive and biomimetic materials for the biohybrid diagnostic and medical devices, and engineered cell and tissue systems. Most recently, he has been working on Project Pathways, an NSF supported Math Science Partnership, in developing modules for a course on Engineering Capstone Design.

\section{Robert Culbertson, Arizona State University}

Robert Culbertson is Associate Professor in the Department of Physics and Astronomy and Associate Director of the Center for Research in Education on Science, Mathematics, Engineering, and Technology (CRESMET) at Arizona State University. He is a member of the Leadership Team in the Math-Science Partnership project, and he leads the development of the MSP course Connecting Physics, Chemistry, and Mathematics. Prof. Culbertson is also actively involved in the Master of Natural Science (MNS) program for in-service science teachers, and he has developed and taught two courses in this program over the past five summers. He also teaches introductory physics for majors and other courses in the physics curriculum. His research interests include Physics Education Research (PER) as well as fundamental experimental research in materials physics specializing in ion beam analysis of surfaces and thin films.

\section{Marilyn Carlson, Arizona State University}

Marilyn Carlson is a Professor in the Mathematics Department at ASU and Director of the Center for Research on Education in Science, Mathematics, Engineering and Technology (CRESMET). Her teaching responsibilities are in the areas of mathematics education. Her research interests are in knowing and learning concepts of precalculus and beginning calculus, problem solving, secondary teacher knowledge, and teacher change. She is currently principle investigator and 
director of the NSF supported Math Science Partnership, Project Pathways: Opening Routes to Math \& Science Success for All Students. 


\title{
Project Pathways: Connecting Engineering Design to High School Science and Mathematics in a Mathematics Science Partnership Program
}

\begin{abstract}
An NSF Math Science Partnership, Project Pathways: Opening Routes to Math \& Science Success for All Students, is targeting mathematics and science learning and achievement in grades $9-12$ by connecting mathematics with context-rich content and processes in science and engineering. The project will produce a research-based and tested model to support secondary mathematics and science teachers in four partner school districts which have demographics mirroring those of Arizona with 45\% minority students. Mathematics, science, engineering and education faculty are teaming with community college master teachers to produce modules for four courses. The courses promote conceptual competence in core content subjects and problem solving process behaviors in scientific inquiry, mathematical problem solving, and engineering design. The unifying concept of understanding and using mathematical function and covariation is applied throughout the courses. Professional learning communities enhance teacher communication and develop shared knowledge that facilitates use of new content and teaching strategies in their own classrooms. The unifying concept, developed in the first pilot Functions and Modeling course, is being integrated into science and engineering topics in the following three courses. An example is its use in the Universal Gas Law for design in the Hot Air Balloon Project. Teacher change in the pilot course showed improved understanding of the function and covariation concept which will facilitate modeling later in engineering design. Language and notational barriers between the mathematics and science teachers were reduced which will facilitate team-based projects in engineering design. Mathematics teachers found science contexts facilitates modeling physical relationships in science and design. Science teachers awareness of mathematics in their own courses increased which will facilitate modeling in engineering design. Additional detail and results are described in the paper.
\end{abstract}

\section{Introduction}

There is a need to improve performance in mathematics and science of high school students in Arizona because fewer than $25 \%$ of Arizona students score "proficient" or higher on the National Assessment of Educational Progress test ${ }^{1}$. Additionally, 43\% of Arizona's Hispanic students, more than $30 \%$ of blacks, and $48 \%$ of Native Americans fail to earn high school diplomas ${ }^{2}$. Minority students who do graduate often cannot meet university admissions requirements because they lack four years of mathematics ${ }^{3}$. Better teachers would help, but preparing them is difficult because, like elsewhere, most Arizona teachers receive limited professional development (PD) support. A recent report concluded that the state's secondary mathematics and science teachers spend an average two days per year in PD activities that focus on deepening knowledge of math and science or improving their methods for teaching those subjects ${ }^{4}$.

To address the issues of teacher preparation and underperforming students, NSF has funded a five-year Math Science Partnership program at Arizona State University entitled, Project Pathways: Opening Routes to Math \& Science Success for All Students. It is based on an in- 
service teacher enhancement model for improving mathematics and science learning and achievement for students in grades 9-12. Research shows that improvements in student learning begin with new models of content-specific PD for teachers. Thus, the overarching goal of the Pathways project is to produce a model that generates a new PD delivery system for supporting secondary STEM (science, technology, engineering and math) teachers' continued professional growth. The model is creating experiences and tools that are shifting the instructional approach in secondary STEM classrooms in order to provide students with the STEM content understanding and process behaviors that will enhance opportunities for success in University STEM courses or majors. The model involves a school/university/community partnership. Core partners include four school districts whose demographics mirror those of Arizona (Chandler, Mesa, Tempe, and Tolleson) and the Center for Research on Education in Science, Mathematics, Engineering, and Technology (CRESMET) at Arizona State University. The supporting partners are the Intel Corporation and Maricopa Community College faculty.

The goal of this paper is to present an overview of the theory, approach, strategy, and activities of Project Pathways, as well as preliminary results on teacher change during the first PD pilot course on Functions and Modeling and the possible impact on the engineering design course.

\section{Approach and Strategy}

The approach addressing previously described issues is development of a model, Figure 1, that institutionalizes the support structures, personnel development, and instructional sequences of a content-focused professional development program as supported by professional learning communities (PLCs). It is being implemented through a sequence of four module-based graduate courses coordinated with school-based PLCs. The on-site activities promote same-school teacher communication, which can enhance pedagogical content knowledge and sustainability of classroom-based reflection. It is also provides teachers with the opportunity to earn a Master's degree of Natural Science (MNS) in content at ASU. The four courses taught or under development include: 1) Functions and Modeling (Spring 2005 and 2006); 2) Connecting Chemistry, Physics and Mathematics (physical sciences) (Fall 2005 and 2006); 3) Connecting Biology, Geology and Mathematics (natural sciences) (Spring 2006 and 2007); and 4) Integrating Mathematics, Science and Engineering (Fall 2006 and 2007).

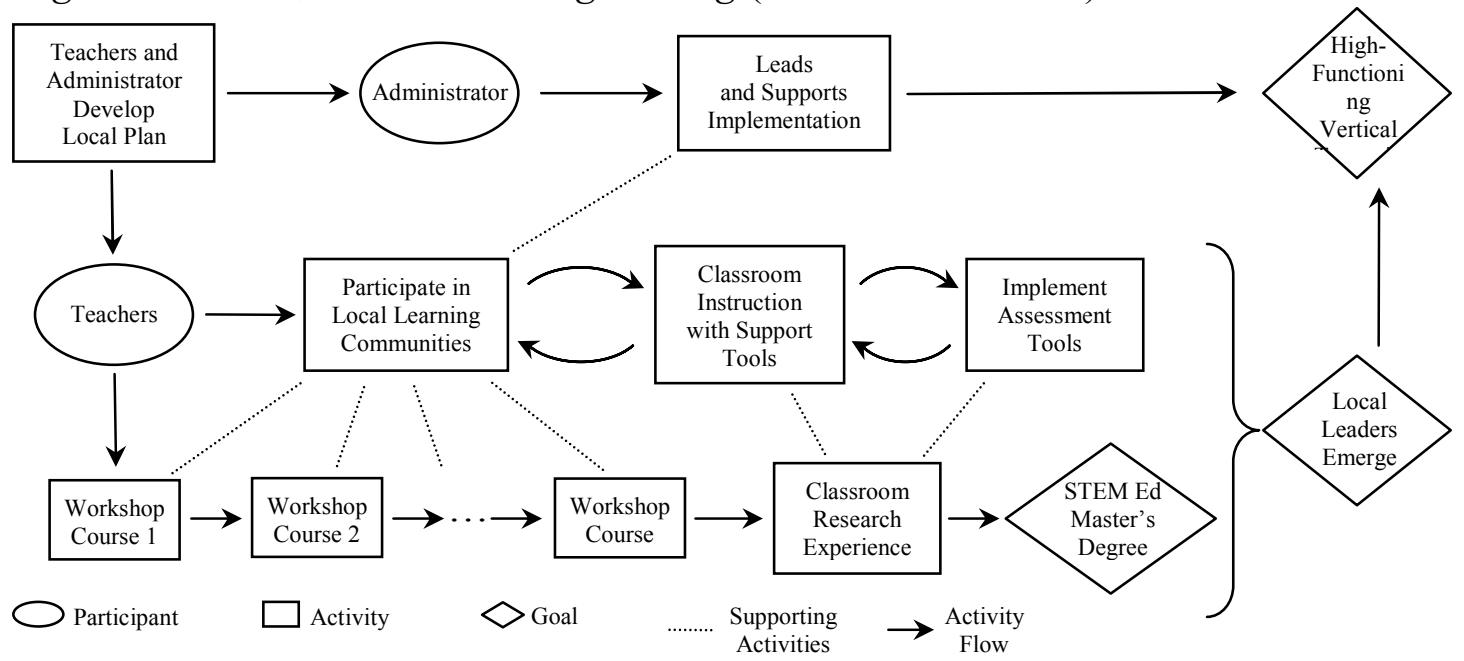

Figure 1. The Professional Support System and Master's Degree for Inservice STEM Teachers 
Each course is being taught to high school science and math teachers from four local school districts with classes of 8 to 30 participants. Courses are taught on-site in each of the four school districts once a week for 3 hours in late afternoon. The composition of teachers is about $55 \%$ mathematics, $25 \%$ biology and the remaining $20 \%$ chemistry and physics. The modules for each course have been developed by teams of 4 to 6 university and community college faculty. In each classroom there are two instructors and two teaching assistants. The instructors may be university or community college faculty or high school master teachers. The professional learning communities are held once a week for one hour and are overseen by a facilitator who is a usually a graduate student. In the first pilot course on Functions and Modeling there was some discussion about classroom practice, but much time was spent discussing homework. The PLC format has been modified for the second cohort Functions and Modeling course with the facilitators receiving much training toward facilitating teachers' metacognition and reflections on their own practice. This has improved the quality of discussion and enhanced understanding of course concepts, content and processes. The model for the PLCs will continue to be refined. The time line for module development and teacher participation is shown in Figure 2.

Figure 2. Module Timeline

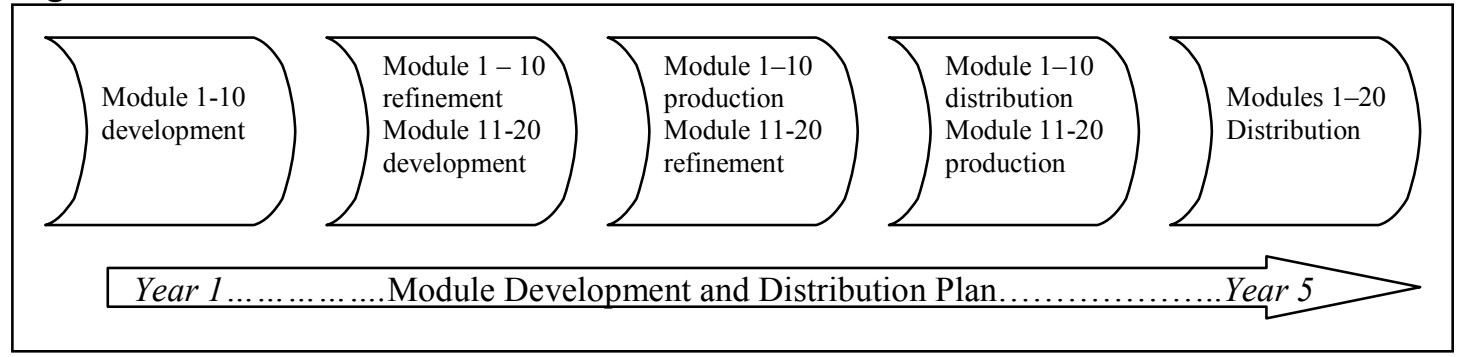

Teacher Participation Timeline
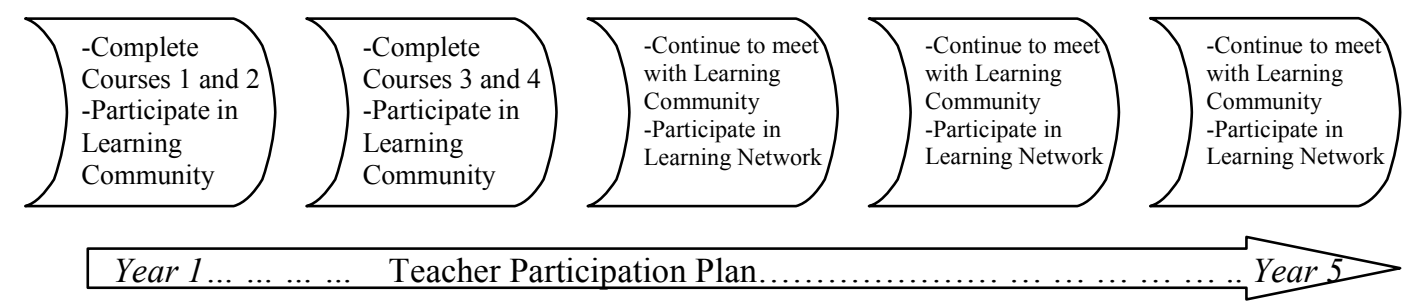

Year $1 \ldots \ldots \ldots \ldots$ Teacher Participation Plan.

The Pathways project is also developing research-based tools to support and assess professional development. They include curriculum and technologies for the graduate courses and also for secondary students, collaboration and reflection tools for PLCs, school-planning tools, and assessment tools to measure change in STEM content knowledge and delivery ability. To help institutionalize the program, a learning network has been created to support the partnership of university faculty, community college faculty, K-12 schools, and industry participants.

The project approach is based on the strategy of promoting teachers' deep understanding of foundational STEM concepts and processes and the connections between them. Research shows that STEM teachers in U. S. schools lack content knowledge and mastery of subject-related pedagogy that enables them to teach content most effectively ${ }^{5}$. They also lack a sense of the connections among concepts that reveal mathematics as an internally logical and coherent system 
of knowledge 6 . This forces teachers to use lectures to deliver content, which emphasizes procedure over engagement. This deters hard-thinking explorations that help develop critical minds with the capability to deeply understanding mathematical, scientific and engineering concepts $^{7}$. In a high minority-population state like Arizona, superficial teaching of STEM subjects disproportionately undermines STEM learning of minority and low-income students ${ }^{8}$.

\section{Theoretical Basis for the Project Design}

The theoretical basis for the project design consists of three facets. The first is the unifying principle of the project, which is the concept of mathematical function and covariation, a strand that runs through the four courses. The second facet is implementation of this concept in the courses through STEM process behaviors. These are the steps that occur in the processes of: a) effective problem solving behaviors; b) scientific reasoning abilities; and c) engineering design processes. The third facet is the use of PLCs, which generate the discussion, dialogue and metacognition that support understanding and reflection on the concept of function and covariation and its use in process behaviors. The research foundation for these three facets in design of the project is discussed below.

The first facet, mathematical function and covariation, is often used by scientists and engineers as a mathematical model of change. Teachers are exploring the concept vertically across grade levels and horizontally across science applications (biology, geology, physics, and chemistry) and engineering design. Understanding function and covariation is essential for students' future success in calculus ${ }^{9}$ and is critical for retaining minority and female students, whose progress in math and science often founders at the precalculus level. The concept is so complex that even high-performing students may exhibit a weak and disconnected understanding of $\mathrm{it}^{10}$. The primary source of this is teachers' weak understandings ${ }^{11}$, which forces them to use a procedural approach to teach functions to their students ${ }^{12}$. Carlson, et al. ${ }^{13}$ have developed guiding frameworks for defining and assessing students' function and covariation knowledge and emerging understanding. The modules in each course feature examples of function and covariation as mathematical models of change that scientists and engineers use to quantify reproducible patterns of phenomena in natural and physical science and engineering design. For example, in biology, a problem solver might model impact of an invasive plant on an ecosystem as a function of its average rate of growth per year. In engineering design, a problem solver could link function and associated covariation in rate of velocity change in Newton's Laws to help describe deceleration in an Egg Drop Project. Sharing instructional approaches between mathematics, the science, and engineering is yielding new ways of making these foundational ideas relevant and accessible to students.

The second facet of the project, STEM process behaviors, provides a unified approach to implementing the concept of function and covariation in the four courses. As stated earlier, the behaviors include: a) effective problem solving behaviors ${ }^{14}$; b) scientific reasoning abilities ${ }^{15}$; and c) engineering design principles ${ }^{16}$. Each process behavior consists of iterations of a series of steps or, in effect, cycles, that lead to a final result. It turns out that the cycles in mathematical problem solving bear similarities to those used in scientific inquiry and in the engineering design process. Each will be discussed briefly. 
In mathematics, problem solving behaviors of strong mathematicians involve intense initial efforts of sense making followed by cycles of the steps of conjecture, test, and evaluate ${ }^{17}$. A well-connected conceptual knowledge is also essential for effective decision making and execution throughout the problem solving process. An emergent four-phase framework (orientation, planning, execution, and checking) provides a detailed characterization of various problem solving attributes (resources, affect, heuristics, monitoring) and their role and significance during each of the problem solving phases. The effectiveness of the problem solvers in making intelligent decisions leading to productive paths is a result of their ability to draw on a reservoir of well-connected conceptual understandings, heuristics, and facts, as well as an ability to manage their emotional responses. This framework is helping guide module development as well as examining emergent problem solving behaviors of secondary STEM teachers and students. The cycles in mathematical problem solving bear similarities to the cycles used in scientific inquiry and the cycles used in the engineering design process. This project's interdisciplinary team facilitates sharing of scientists, mathematicians, and engineers disciplinary approaches for helping learners understand complex concepts.

In science, the development of reasoning abilities/skills/patterns has also been the subject of a long line of research within developmental psychology and science education ${ }^{15}$. The scientific method, as simplified, consists of cycles of the steps of observation, hypothesis, prediction, verification by experiment, and evaluation. This cycle is then iterated to refine, modify, or refute the hypothesis. Understanding and use of such as a reasoning pattern plays an important role in the ability to do science and to construct science concepts. Consequently, among the project's goals is helping teachers and students develop general hypothesis-testing skills by encouraging them to raise, and answer, questions that emerge during lab activities.

In the engineering design process, the goal is to solve a technological problem or create a technological process, artifact or system. In the design cycle there is a series of steps employed, which are usually iterated as cycles, to achieve the end result ${ }^{16}$. Briefly, the design process may consist of the following steps: define a problem or need; specify the functional requirements and constraints to be fulfilled; brainstorm alternative solutions; evaluate solutions based on the criteria in requirements and constraints; use the proposed solution to fabricate a prototype and create an associated mathematical model; test and evaluate the prototype and model; and iterate to refine or modify the solution or, select another solution. In order to fully implement the design process, the concept of function and covariation must be used in conjunction with the scientific principles that describe the physical phenomena associated with the proposed design solution. Thus, in the Pathways project, the first course in Functions and Modeling, and the second and third courses in science, provide a critically necessary foundation for the activities and design projects in the Integrating Mathematics, Science and Engineering course.

In the third facet of the project, PLCs, research indicates that one of the best ways for teachers to improve their knowledge and skill is to spend more time not with their students, but with their colleagues $^{18}$. The National Partnership for Excellence and Accountability in Teaching ${ }^{19}$ suggests $^{2}$ that teachers are more likely to change when they feel involved and supported in a collegial community of learners. DuFour \& Eaker ${ }^{20}$ define highly effective professional learning communities as ones in which: 1) teachers gain conceptual and pedagogical knowledge and 2) transfer that knowledge into observable and quantifiable improvements in their classroom 
practices that 3) lead to increased student learning. An approach this project is using in organizing effective teacher learning communities is having teachers explore challenging content and problem solving in teams ${ }^{21}$.

\section{Program Objectives}

The Pathways program has eight measurable objectives that are being assessed by a variety of instruments and techniques such as surveys, concept inventories, focus groups, and classroom videos. The details of these instruments will not be discussed here except for those that have been used later in the section describing initial preliminary results. The objectives listed below have target audiences associated with the project who are; high school teachers, high school students, introductory course college teachers, introductory course college students and community college teachers. While all of the Pathways program objectives are listed below, only initial preliminary results will be reported for secondary math and science teachers for the first course, as well as the potential impact later on the engineering design course. Future reports will expand the target audiences and remaining courses as the project progresses. The objectives for the Pathways program include:

- Shift teachers' practice to inquiry and project-based methods,

- Increase teachers' ability to reflect on, monitor, and adjust their classroom practices,

- Deepen teachers' understanding of mathematics, their knowledge of mathematical connections, and their ability to use mathematics in science and engineering design applications,

- Increase secondary student achievement in math and science,

- Close the achievement gap of minority secondary students in each school,

- Improve students' problem solving, scientific inquiry and engineering design strategies (termed STEM process behaviors) and confidence in their STEM abilities,

- Measure shifts in teacher practice and student conceptual learning in ASU's introductory precalculus, calculus, physics, engineering, and other STEM courses,

- Improve success rate in ASU introductory precalculus, calculus, physics, and biology courses.

\section{Preliminary Results}

This section will focus on the preliminary results of the first pilot course offered in the Pathways project, Functions and Modeling. The class resources for the first pilot course are available on http://cresmet.asu.edu/proj_res/msp/index.html. The emphasis was on the understanding and use of concept of mathematical function and covariation. The five functions utilized during the course were: linear; quadratic; general polynomial; exponential; and trigonometric.

The concept of function and covariation was quantitatively assessed by the Precalculus Concept Assessment (PCA), a validated instrument developed by Carlson ${ }^{22}$. The PCA was administered on the first and last nights of class. There was a small but significant gain in achievement in the results of the PCA, but the goal was to test the suitability of the instrument for the particular population and content of the pilot math course. Both the course content and the items used in 
the assessment have been modified to adapt them for the next time the course is taught, which is during this Spring 2006 term. For the 4 sites, the average test scores are shown below:

Figure 3. Pretest and Posttest Scores for the PCA for Four School Districts

\begin{tabular}{|l|l|l|}
\hline Site & Pretest average score & Posttest average score \\
\hline Tolleson & 11.4 & 13.2 \\
Mesa & 13.9 & 16.6 \\
Tempe & 14.6 & 19.2 \\
Chandler & 12.5 & 15.4 \\
\hline
\end{tabular}

Note that the overall pretest average was 12.7 and the overall posttest average was 16.1. There was no significant difference among the mean baseline scores in the 4 classes; however, we note that 14 of the teachers who took the pretest did not complete the posttest. The teachers who dropped out had a mean score of 8.7 on the pretest, while the teachers who stayed to complete the posttest had a mean score of 13.5 on the pretest ( $p$-value $<.05)$. Although the mean post-pre difference is highly significantly different from 0 (mean $=2.66$, $p$-value $<.01)$, the difference cannot necessarily be ascribed to the courses. Due to the late start in enrolling teachers in the project, there was only a limited comparison group available, and they were only given the posttest. The average PCA score from our comparison group was 12.7. The observed difference in scores for teachers in the course, therefore, could be due to regression to the mean, or to learning the test, or to self-study, or other factors.

Below is a graph of the pre-post scores for the 4 classes. In the graph, each symbol represents the pre ( $\mathrm{x}$ axis) and post (y axis) score for a teacher. Note that circle is Tolleson, triangle is Mesa, $\mathrm{x}$ is Tempe and + is Chandler. The line drawn on the graph is the $\mathrm{y}=\mathrm{x}$ line; anyone above that line did better on the posttest than on the pretest. As can be seen from the plot, almost every teacher who took both pre- and posttest did at least as well on the posttest as on the pretest.

Figure 4. Graph of Posttest PCA Score vs. Pretest PCA Score

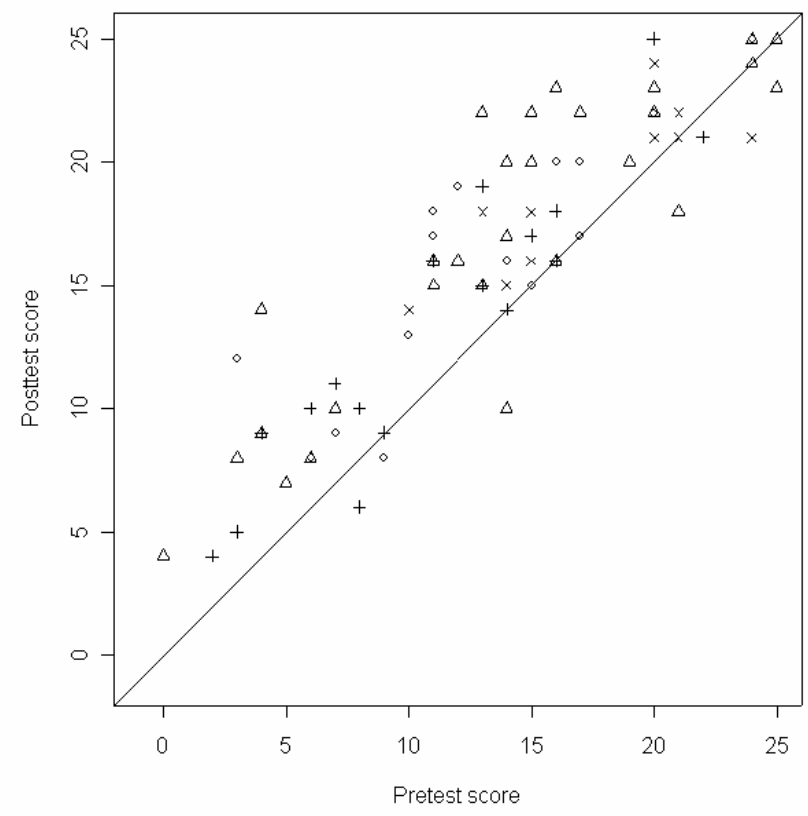


In addition to improvement shown in the PCA, qualitative assessment showed that teachers were able to recognize different types of rate of change (such as those arising from linear, quadratic, or exponential functions) and were regularly able to describe what different types of rates meant in terms of a graph, a table of numerical data, or a physical situation. However, they experienced difficulty trying to use rate of change information to determine something else, especially problems posed in a physical context. Qualitative assessment also found most teachers had difficulty describing the meaning of various function parameters, either mathematically, or with respect to a problem context. These issues will be addressed by emphasizing contextualization of functions and on determining and interpreting parameters in the next Functions and Modeling course during Spring term 2006.

An overall summary of general trends of teacher change during the semester are listed below with some details following. The trends, and their potential impact on the science and engineering design pilot courses, show that:

i) the teachers' understanding of the function and covariation concept improved which will facilitate modeling later in science and engineering design;

ii) language and notational barriers between math and science teachers were reduced which will help in the team-based projects later in science and engineering design; iii) mathematics teachers became aware of science contexts for using the function and covariation concept which will facilitate modeling physical relationships in science and their application in engineering design;

iv) science teachers report that the course has increased their awareness of how prevalent mathematics is in their own courses, which will facilitate the use of mathematical models in the science and engineering design courses.

Teacher metacognition and awareness of their own practice increased during the pilot course. They were asked to reflect on one aspect of their practice and try to improve it by discussing what changes they made, and whether those changes had been sustained. There was a variety of responses, mostly positive, which included: providing more closure/summarizing; questioning (both methods and types of questions); analyzing student work; brainstorming prior knowledge with students; calling on all students; using calculators; and using more positive classroom management techniques with more consistent consequences.

Analyses of qualitative data on teachers' pedagogical content knowledge was focused on teachers' understanding of relevance of various function models to the sciences and of students' misconceptions. After experiencing initial difficulty, teachers felt they developed an eventual understanding of function and covariation and function types and relevance of those to science content. Teachers' understanding of student thought processes and student misconceptions increased during the pilot course. They reported on their experience of interviewing a student doing a multiple choice problem of their choice. Most teachers commented that this was a beneficial experience because they: got to know more about what a student thought; gained insight into students' problem solving techniques (or lack thereof); and got a better understanding of where their students really stood in terms of mastering some concept. 
Generally, teachers found difficulty in executing classroom transfer (i.e. adapting Functions pilot course content and process to their classrooms) from the weekly Functions pilot course. Many felt at a loss when thinking about implementing similar activities. Reasons included; not having enough time, not feeling confident enough about material, and believing that the content was beyond the abilities or needs of their own students. Most teachers, however, said that they planned to take back general ideas from the Functions pilot course into their own classrooms. These included questioning techniques, group-work strategies, and small portions of lesson activities. This indicates a positive shift in teaching practice.

Although teachers had difficulty in transferring weekly content of the Functions pilot course to their own classroom, when enough time was given to do this, as with the final project, teachers were generally successful. This was determined by reflections on the project, in which they were asked to create a model-eliciting activity in which students had to create a written record of their thinking on some concept. Most teachers commented that the activity was beneficial for a variety of reasons. These included: asking kids to write, which is difficult but necessary; it helped to bring closure to a unit; students got to be creative; they learned of their students' misconceptions; and they saw what their students were thinking.

The impact of the professional learning communities was quite positive. The most common response to the question, "What have you liked most about the course?" was the opportunity to work with other math teachers and other science teachers. They commented extensively on the positive interactions they had with each other and how they learned from each other.

Overall, the initial preliminary results presented and discussed demonstrate that the first three program objectives listed earlier, which relate to teacher practice, reflection, and understanding have been moderately well satisfied. The course will be modified to enhance these gains when taught to future cohorts of teachers. Thus, the first pilot course on the concept of function and covariation and associated processes has laid a foundation for the horizontal application of the concept across the next three pilot courses in the sciences and engineering design.

\section{Conclusions}

This paper has described for the Pathways project the need, approach, theory, objectives, implementation, as well as the preliminary results of the first pilot course, Functions and Modeling. The potential impact on the science and engineering designs course was discussed. Generally, students and faculty, in both high school and college, assume there are implicit, useful, and well-understood linkages between math, science and engineering. However, preliminary results demonstrate that, between disciplines, there are gaps in knowledge, issues in terminology, and differences in ways of thinking about function and covariation and its application. The opportunity for university, community college, and grade 9-12 teachers to cross disciplinary boundaries with dialogue, content creation, and teaching activities is deepening each individual's understanding of function and covariation, and also content and STEM process behaviors across math, science, and engineering. The ultimate benefactors of the impact of the Pathways project are the grade 9-12 and university students who will experience contextualized content, the enhanced pedagogy, and the richer connections between disciplines. 


\section{Acknowledgement}

The National Science Foundation supported this work via MSP Grant 0412537.

\section{References}

1. National Center for Education Statistics. (2003). National assessment of educational progress: The condition of education 2003 in brief. Washington, D.C.: U. S. Dept. of Education.

2. Intercultural Development Research Association for the Arizona Minority Education Policy Analysis Center (2002). Dropping out of Arizona's schools: The scope, the costs, and successful strategies to address the crisis. Phoenix, AZ: Arizona Commission for Postsecondary Education. Available at www.acpe.asu.edu.

3. Arizona Minority Education Policy Analysis center (2003). Arizona minority student success report. Phoenix, AZ: Arizona Commission for Postsecondary Education. Available at www.acpe.asu.edu.

4. Sowell, E. (1995). K-12 Science and Mathematics Education in Arizona: A status report. A report to the Arizona Board of Regents. Phoenix, AZ: ABOR.

5. Monk, S., \& Nemirovsky, R. (1994). The case of Dan: Student construction of a functional situation through visual attributes. CBMS Issues in Mathematics Education, 4.

6. Cooney, T., \& Wilson, M. (1996). Teachers' thinking about functions: Historical and research perspectives. In T. A. Romberg \& E. Fennema (Eds.), Integrating research on the graphical representation of functions (pp. 131-158). Hillside, NJ: Lawrence Erlbaum.

7. Stigler, J., and Hiebert, J. (1999). The teaching gap: Best ideas from the world's teachers for improving education in the classroom. New York: The Free Press.

8. Borman, G., Stringfield, S., \& Rachuba, L. (2000). Advancing Minority High Achievement: National Trends and Promising Programs and Practices. New York: College Entrance and Examination Board.

9. Carlson, M.; Jacobs, S. Larsen, E. (2001a). An Investigation of Covariational Reasoning and Its Role in Learning the Concepts of Limit and Accumulation. North American Chapter of the International Group for the Psychology of Mathematics Education Conference Proceedings, 2, 517-523.

10. Carlson, M. (1995). A Cross-Sectional investigation of the development of the function concept, unpublished Ph.D. Dissertation, Department of Mathematics, University of Kansas. 
11. Thompson, P. W. (1994). Students, functions, and the undergraduate curriculum. In E. Dubinsky, A. H. Schoenfeld, \& J. J. Kaput (Eds.), Research in Collegiate Mathematics Education, 1. Issues in Mathematics Education, 4.

12. Carlson, M. (2000). A Study of the Problem Solving Behaviors of Mathematicians: Metacognition and Mathematical Intimacy in Expert Problem Solvers. Proceedings of the $24^{\text {th }}$ Conference of the International Group for the Psychology of Mathematics Education, 2 , 137-144. Columbus, Ohio: Eric Clearinghouse.

13. Carlson, M.; Jacobs, S.; Coe, E., Larsen, S.; Hsu, E. (2002). Applying Covariational Reasoning While Modeling Dynamic Events: A Framework and a Study. Journal for Research in Mathematics Education, 33, 352-378.

14. Schoenfeld, A.H. (1992). Learning to think mathematically: Problem solving, metacognition, and sense making in mathematics. In D.A. Grouws (Ed.), Handbook of research on mathematics and teaching. New York: Macmillan.

15. Lawson, A.E. (1995). Science teaching and the development of thinking. Belmont, CA: Wadsworth.

16. Pahl, G., and Beitz, W. (1989). Engineering design: A systematic approach. New York: Springer-Verlag.

17. Carlson, M. P. (1998). A cross-sectional investigation of the development of the function concept. In A. H. Schoenfeld, J. Kaput, \& E. Dubinsky (Eds.), CBMS Issues in Mathematics Education: Research in Collegiate Mathematics Education III, 7, 114-162.

18. Newmann, F.M., \& Wehlage, G.G. (1995). Successful school restructuring: A report to the public and educators by the Center on Organization and Restructuring of Schools. Washington, DC: American Federation of Teachers. (ERIC Document No. ED387925)

19. Cibulka, J. (2000) Practitioners' Guide to Learning Communities. The Creation of HighPerformance Schools Through Organizational Learning (RFP-97-0101, Project 4.4.1), Washington, D.C.: National Partnership for Excellence and Accountability in Teaching.

20. DuFour, R., and Eaker, R. (1998). Professional learning communities at work: Best practices for enhancing student achievement. Bloomington, IN: National Educational Service.

21. LaChance, A., and Confrey, J. (2003). Interconnecting content and community: A qualitative study of secondary mathematics teachers. Journal of Mathematics Teacher Education, 6.

22. Carlson, M., Oehrtman, M., \& Engelke, N. (submitted). The development of an instrument to assess precalculus students' conceptual understandings: The Precalculus Concept Assessment Instrument. 